\title{
THE MOSE MACHINE
}

\section{An anthropological approach to the building of a flood safeguard project in the Venetian Lagoon}

[Received February 1st 2021; accepted February 16th 2021 - DOI: 10.21463/shima.104]

\section{Rita Vianello}

Ca Foscari University, Venice <rita.vianello@unive.it>

\begin{abstract}
This article reconstructs and analyses the reactions and perceptions of fishers and inhabitants of the Venetian Lagoon regarding flood events, ecosystem fragility and the safeguard project named MOSE, which seems to be perceived by residents as a greater risk than floods. Throughout the complex development of the MOSE project, which has involved protracted legislative and technical phases, public opinion has been largely ignored, local knowledge neglected in favour of technical agendas and environmental impact has been largely overlooked. Fishers have begun to describe the Lagoon as a 'sick' and rapidly changing organism. These reports will be the starting point for investigating the fishers' interpretations of the environmental changes they observe during their daily fishing trips. The cause of these changes is mostly attributed to the MOSE'S invasive anthropogenic intervention. The lack of ethical, affective and environmental considerations in the long history of the project has also led to opposition that has involved a conflict between local and technical knowledge.
\end{abstract}

KEYWORDS: Venetian Lagoon, acqua alta, MOSE dams, traditional ecological knowledge, small-scale fishing.

\section{Introduction}

Sotto acqua stanno bene solo i pesci

[Only the fish are fine under the sea $]^{1}$

This essay focuses on the reactions and perceptions of fishers facing flood events, ecosystem changes and the safeguarding MOSE (Modulo Sperimentale Elettromeccanico 'Experimental Electromechanical Module') project in the Venetian Lagoon. This subject emerged during my ongoing research on the traditional fishing culture of the Lagoon, where I have investigated local knowledge and particular conditions. On occasions during my research, fishers began to describe the Lagoon to me as a sick' and rapidly changing organism. These reports were the starting point for investigating the fishers' interpretations of the environmental changes that they have observed during their daily fishing trips. Their accounts describe variations in the animal and plant species living in the Lagoon and recent changes in geomorphology. These changes are attributed to invasive anthropogenic interventions and the present-day imbalance of the tidal currents in particular, which impacts on the acqua alta, peak high tide events that submerge inhabited areas. The

\footnotetext{
${ }^{1}$ From an interview with a Venetian fisherman. He explained that the sea is the fishes' environment, and it is not for human machines like the MOSE.
}

Shima <www.shimajournal.org> ISSN: 1834-6057 
narrative is specifically contemporary and relates to the wider dimension of safeguarding against global climate change and rising sea levels all over the world.

Currently, there are many discussions around environmental policies with ethical codes shared by the social actors involved. The socio-anthropological sciences have been applied to environmental issues related to the phenomena of the Anthropocene for some time, addressing many aspects of the complex and vast topic. They have highlighted that environmental issues at the political level seem to be limited to the management of risks, their evaluation and social acceptability. Each society has its own vision of nature and only in recent times have people began to question human duties towards nature and felt the need transcend an anthropocentric vision in order to develop a principle of responsibility towards the future of our planet (Rolston, 1988; Jonas, 1990). In this context, the continuing debate on the safeguarding of the Venetian Lagoon is a significant case-study as it exemplifies a technocentric vision of the environment.

The research presented here is based on qualitative anthropological methodology, such as semi-structured interviews with residents, fishers, environmentalists, opposition groups, researchers and experts in hydraulic engineering. All quotations from these sources in the text are translations by the author. The article is also informed by the critical reading of various texts on the topic (social media content, newspaper articles, blogs, videos, songs and television programmes) and is an example of auto-ethnography - a recent approach to anthropological studies in which the experience of a scholar itself becomes an object and part of the analysis ${ }^{2}$ - and in which my individual engagement with the specific local sociocultural and political context is analysed.

\section{The context: the Venetian Lagoon and fishing}

The Venetian Lagoon is located between the sea and the mainland. Due to this, it is unstable and, in many respects, it embodies what has been identified as the "hybrid" nature of deltas (Lahiri-Dutt, 2014). Therefore, the Lagoon can be considered a typical transitional ecosystem, an unstable border between sea and land, between the freshwater of the rivers and the saltwater of the sea, where the landscape changes according to the tides. Where there was once water, the seabed emerges, populating the Lagoon with small islands which are destined to disappear again within a matter of hours. In past centuries, the Lagoon's morphology was shaped by the currents generated by the tidal flows on one hand and the contribution of rivers on the other, creating - starting from the inlets - a vast network of submerged canals. Venice is the largest coastal lagoon in the Mediterranean basin, with a length of about $50 \mathrm{~km}$, a width between 10 and $12 \mathrm{~km}$ and a total area of about 550 square $\mathrm{km}$. The average depth of its seabed is just 2 metres, although in some areas it can be measured up to 20 metres (Venice Province Fishing Plan, 2015). Two elongated islands that extend from north to south separate the sea from the Lagoon: the island of Lido, in the north, and the island of Pellestrina, in the south. Water is the dominant element. It covers $67 \%$ of the total area of the Venetian Lagoon area and only $8 \%$ of the Lagoon's surface is taken up

\footnotetext{
${ }^{2}$ Ellis, Adams and Bochner describe autoethnography as "an approach to research and writing that seeks to describe and systematically analyse (graphy) personal experience (auto) in order to understand cultural experience (ethno)... This approach challenges canonical ways of doing research and representing others... and treats research as a political, socially-just and socially-conscious act... A researcher uses tenets of autobiography and ethnography to do and write autoethnography. Thus, as a method, autoethnography is both process and product" (2011: online).
} 
by the islands (the remainder are marshy areas) (UNESCO, 1995). The connection with the sea is maintained by three natural entrances, often referred to as 'harbour mouths' that offer passage into the safe Lagoon waters: the Lido inlet in the north, the Malamocco entrance in the centre and the Chioggia harbour entrance in the south. In economic terms, fishing has always been one of the most important activities in the area. Over the centuries, many local communities have depended on the exploitation of aquatic resources and this has led to the development of a particular culture, distinct from the farming one widespread in the Venetian hinterland.

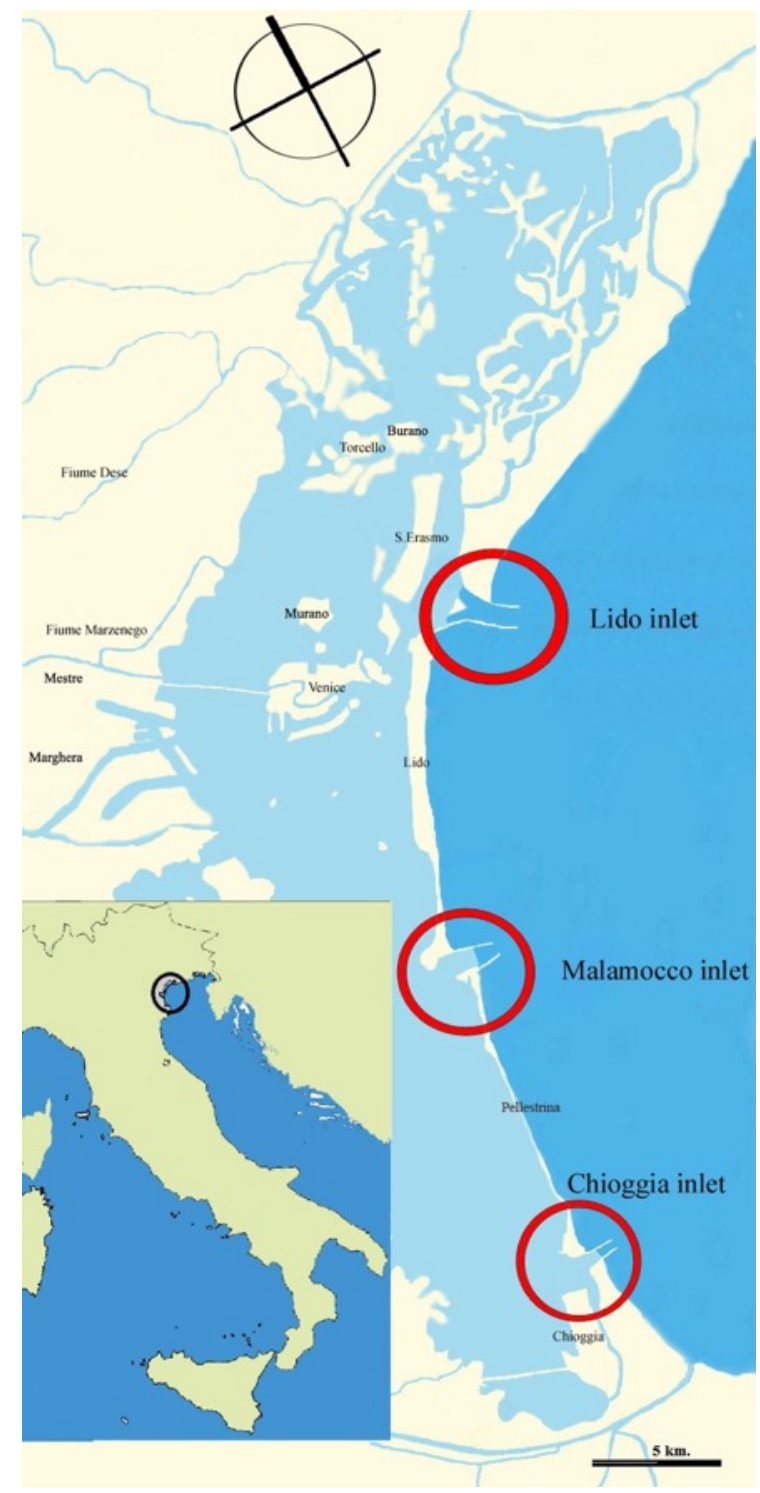

Figure 1 - The three inlets in the Venetian Lagoon (GIS elaboration by Maurizio Vaccari; cartographic base: Touring Club Italiano). 
In past centuries, numerous interventions were carried out by the Serenissima Republic of Venice in order to maintain the equilibrium of the unstable place. This is an instability that local fishers are well aware of. Among fishers we encounter an old proverb which reminds us that carrying out even a single, apparently insignificant, intervention can have consequences on the geomorphology of places. An old fisherman with whom I often conversed used to always remind me that "even a pole makes a swamp", in order to explain to me that the Lagoon has its own very delicate balance that must never be altered, at risk of transforming it. But in the last 150 years, human activities have contributed as never before to profoundly changing the Lagoon. The Lagoon is beginning to be subjected to an invasive series of anthropic interventions in the name of progress and modernity (Vianello, 2017: 197-219), ${ }^{3}$ the latest of which, historically, is the MOSE system.

As Hewes (1948) points out, fishing is a form of domestication that allows communities their own special skill sets, which are productive, cultural and social at the same time. In fact, fishing is a set of resource acquisition practices, similar to hunting but also more refined, as the marine environment, with its seabed and the plant life and animal species is not visually perceptible. For this reason, the fishers of the Lagoon have developed, and adapted when necessary, a whole complex set of technical and naturalistic perceptions and knowledge over the years, especially concerning the morphology of the submerged territory, that are of exclusive local and aquatic relevance. Places have also been assigned names that are not always translatable. For example, it is common to hear fishers talk about:

- baréne, a type of islet which is only submerged during the highest tides;

- vèlme, areas that emerge during accentuated low tides; and

- ghèbi, very small canals (Bonesso, 2004).

Sometimes the fishers make strings of conceptual associations in words and images using the human body in reference to the Lagoon's denomination:

We used to fish on the zensive [edges - literally 'gums'] of the canals, and the testa [top - literally 'head'] of the dams in the winter. In spring we even sometimes fished the novello [young] fish at the foot of the dams. (Gianfranco $\mathrm{V}$, interview, 2004)

The Lagoon, as a whole, is also identified by fishers using references to the human body. They think of it as 'the uterus of the sea' when they wish to highlight that it's the privileged reproductive area of many aquatic species. This confirms what has been reported by Strang (2004) in her study of water. She writes that humans share the same models as cognitive starting points. These are ubiquitous, occurring in every language, and in every sphere of experience, included the aquatic sphere.

There are different situations among the fishers of the Lagoon today. In the northern area, where the island of Burano has remained the main fishing centre, Lagoon fishing activity is still multi-specific and multi-tool, that is, directed towards various types of products and multiple techniques. It is a type of fishing commonly referred to as 'traditional' as it still uses

\footnotetext{
${ }^{3}$ Among the most invasive have been the construction of the railway bridge in 1846 which connected Venice to the mainland for the first time, transforming it into a peninsula; the construction of the industrial area of Porto Marghera between 1917 and 1925; and, finally, the reclamation of lagoon areas for agricultural purposes.
} 


\section{Vianello - MOSE machine}

artisanal techniques and tools from the past. Furthermore, it is diversified according to the seasons and available resources. Knowledge in artisanal fishing is mainly based on direct experience derived from daily presence in the Lagoon. This knowledge is transmitted from the oldest to the youngest, each fisherman then developing their own strategies by modifying and, less often, innovating, their set of skills and practices. In the southern Lagoon, in the fishing centres of Chioggia and Pellestrina, industrial sea fishing and shellfish farming are most common, although small scale Lagoon fishing is still present. Unfortunately, even in the northern Lagoon, small-scale artisanal fishing is in difficulty due to the presence of new currents and the increased tidal flows. These changes appeared after interventions were carried out at the inlets in order to facilitate the MOSE structures.

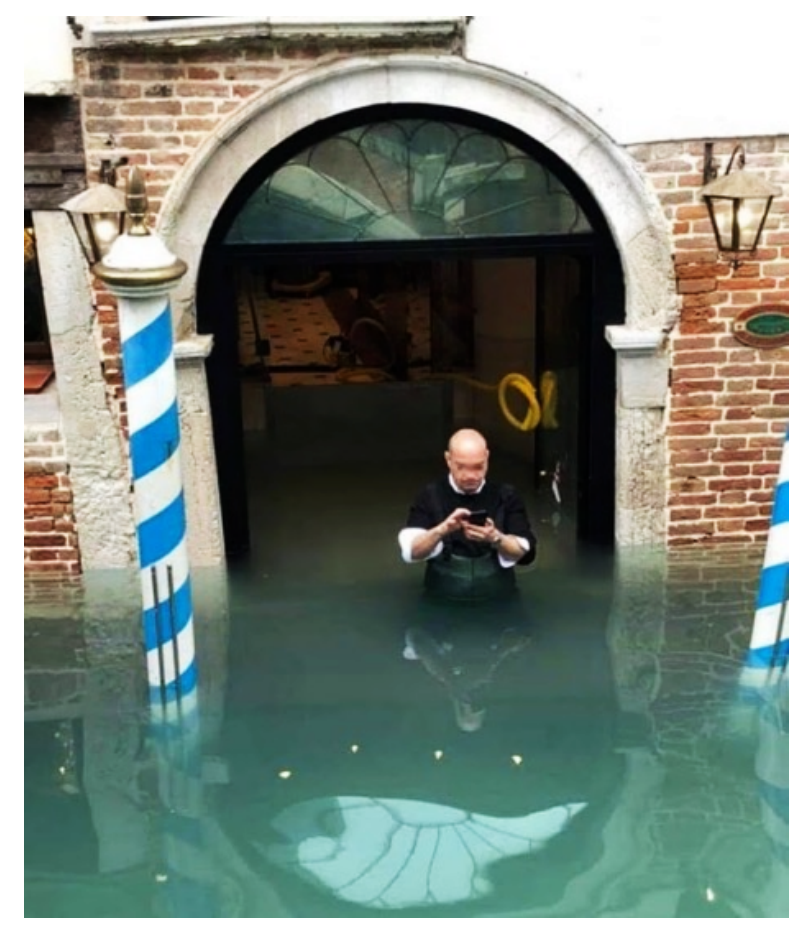

Figure 2 - a typical aqua alta situation in Venice (author's photo, 2019).

\section{Environment: a polysemous concept}

Before addressing the specific issue of MOSE, it is necessary to clarify what is really meant by the term 'environment'. The concept, progressively defined in the interaction between the social field and scientific field, possesses a vast polysemy (Guerrini and Muxart, 1989; Godard, 1992), as also evidenced by the etymology of the term which does not designate a clearly delineated reality. Various of its definitions refer to the opposition between what is physically around us - i.e. the physical, biophysical environment - and the economic-social and cultural context in which actors or social groups carry out their activities.

The 1960s and 1970s saw the birth of environmental movements and the definition of environment, like the concept of nature, became disconnected from the meaning of place, (considered as a physical space, separate from the world of living beings), and assumed a 
more conflictual connotation as the problems of nature are often linked to human action (Breda, 2019). In recent years this tendency has spread, with the media using the word 'nature' as a synonym for the natural environment, including landscapes shaped by humans and, thereby, anthropised through such modifications. This perception has led to the phenomenon of the "culturalization of nature", whereby nature is transformed into something increasingly artificial (Trupiano, 2014). This transformation forms the basis of an anthropocentric ecological vision that does not consider the complexity of the multispecies relationships that comprise each environment (Mathews, 2019; Tsing, Matthews and Bubandt, 2019). While this anthropocentric vision is widespread in Western cultures, many non-Western - and, particularly, Indigenous - societies do not contemplate a clear separation between humans and their environment and, consequently, do not hypothesise any discontinuity between humans and non-humans (Descola, 2005) ${ }^{4}$. In reality, as Ingold (2008) asserts, we all live immersed in a human-environment-nature "entanglement" wherein humans and non-humans are all equally active subjects. According to Tsing (2019), distinct species interlace with each other to form complex multi species relationships in a constant dialogue that contributes to maintaining the balance of ecosystems. As he has also asserted:

interspecies entanglements that once seemed the stuff of fables are now material for serious discussion among biologists and ecologists, who show how life requires the interplay of many kinds of beings (2015: vii).

In the light of this brief survey of the polysemic meanings of the term 'environment' it is possible to affirm that even an environment characterised by water, such as the Venetian Lagoon, is the product of a complex intertwining of human and non-human transformative processes and therefore bio-social construction. But it should also not be forgotten that every natural environment is also modified by causes that are not attributable to human action, even though every human settlement always involves modifications to the ecosystems whose resources are exploited. For this reason, the impact of human action on physical spaces and its repercussions on the ecosystem (today, more than ever) should not be overlooked. This is a process that began with the Industrial Revolution and which has been accelerating more and more in recent centuries with the rise of capitalism as the dominant economic model (Alliegro, 2019). To underline the ever-increasing speed of changes to the environment made by humans, many scholars have begun to consider this historical phase of ours as a new geological epoch following the Holocene, naming it the Anthropocene. The concept of Anthropocene began to spread around the 2000 s thanks to the work of various scholars and in 2009 it was defined and formulated by Johan Rockström and collaborators at the Institute for Resilience of the University of Stockholm. They defined planetary limits and highlighted how human societies (or rather industrial societies) must be considered as geological forces capable of transforming the planet (Glaser, Ratter, Krause and Welp, 2012). Moore, entering the debate on the political, economic and technological systems that produced the new geological era, proposed the term 'Capitalocene' in order to highlight that the origins of this new Era can be traced back to the development of capitalism (Moore, 2017; also see Lai 2020) $)^{5}$. The need to study the phenomena which characterise the Anthropocene has led to the development of a new dialogue between professionals in the natural sciences and

\footnotetext{
${ }^{4}$ We recall Descola's studies on the historical evolution of the nature/culture break. This opposition appeared belatedly in the course of the development of Western thought but has now lost its presumed universality because it makes no sense for those who are not "modern" Westerners (Descola, 2005).

${ }^{5}$ For all these reasons, current research on environmental issues is increasingly binding with the anthropological studies of crisis and risk (Allegro, 2020).
} 
Humanities, who question some of the basic assumptions of Western science and thought (Ingold and Simonetti, 2018).

\section{The Venetian lagoon as an aquapelagic assemblage}

From a geographical point of view, the Venetian lagoon can be considered a small and protected archipelago made up of numerous islands and islets close together, sometimes joined by bridges to form a larger settlement area. The term archipelago commonly indicates a group of small islands quite close to each other with similar morphological characteristics. However, this is a rather vague and imprecise concept which is generally limited to geomorphological aspects. Studies have, for a long time, neglected the cultural aspects in favour of the physical ones, which inevitably develop from the interaction between humans and the environment in which they live. The aquatic spaces existing among the islands must not be interpreted as a separating factor but must also be understood as an aggregating one and a source of cultural interaction among small-social groups (Nash, 2016: 2; Farinelli, 2021). This gap has been filled thanks to a recent interesting conceptual approaches to Island Studies developed over the last decade that propose that an archipelago should not be understood exclusively as a geographical set of islands but as a complex dimension which also includes the spatial depths of the water (Fleury, 2013: 1). Each archipelago can be understood as the result of a human process, therefore a cultural product, in which the aquatic spaces can be understood as fundamental for the sustenance of the community, for the construction of the local sense of identity and of one's own imaginary. It has been posited that when there is a mutual interpenetration between terrestrial and aquatic space for livelihood purposes in which the interaction between different actors, animate and inanimate are fundamental this can be understood as aquapelagic (Hayward, 2012a, 2012b). Hayward describes an aquapelagic assemblage as:

a social unit existing in a location in which the aquatic spaces between and around a group of islands are utilised and navigated in a manner that is fundamentally interconnected with and essential to the social group's habitation of land and their senses of identity and belonging. (2012a: 4)

On the basis of the testimonies collected from fishers presented in this article, the waters of the lagoon, with its islands and the communities that they host, fall within the definition of aquapelagic assemblage. This particular space hosts human (and non-human) communities within an environment that develops simultaneously within the terrestrial and aquatic dimensions. However, it is important to keep in mind that not all communities living on islands or in coastal areas develop an "aquatic/marine" culture. Using the words of the anthropologist Mondardini Morelli, it is possible to more precisely define which societies fall into the latter category:

maritime societies [that] have differentiated themselves from others in regard to the domestication of the sea have ultimately developed a productive, social and cultural specialization. This productive, social and cultural specialization can be referred to, for the purpose of analysis, as the "culture of the sea". (1990: 5)

This is a peculiarity that makes the places of study particularly interesting. In the specific case of the Venetian lagoon, its aquapelagic dimension has developed thanks to the interisland relationships and connections which possess various cultural, linguistic and social 
elements that present themselves with similar patterns in each distinct community. At the same time each island has also developed its own original slight variations together with its own sense of identity. In fact, the Venetian islands have common but not identical elements that make them micro-worlds distinct from those of neighbouring communities. We can also encounter small peculiarities within the city of Venice itself. Between one sestièr (district) and another, the way of pronouncing the local dialect can vary, or there may be an additional sense of identity that makes an inhabitant perceive themselves as a lagoon resident, a Venetian, but also as an inhabitant of a certain city area. These are socio-cultural elements that are found to be accentuated in the islands. In these islands there is a strong sense of identity of belonging to the Lagoon and to the city of Venice that makes its inhabitants feel part of a socio-cultural group distinct from those who live in the neighbouring mainland. At the same time the 'Venetianness' is flanked by a parallel sense of identity of the island. In the past, this sense of identity could also lead to rivalry between different islands. As for the linguistic aspect, there are differences in pronunciation and intonation, in expressions, as well as variations in vocabulary between the islands of the north and south lagoon. The most interesting aspect is represented by the professional jargons. Take the lagoon fishers for example, who use the same techniques and fishing gear, and fish for the same prey, but who often refer to such elements with different dialectal names.

Even the well-rooted cultural dimension of "Venetianness" is now severely tested by the global challenges of the Anthropocene. It is an unequal and complex survival challenge where the disappearance of the local lagoon culture is at stake. In this battle, the solutions adopted for the safeguarding of the lagoon are sometimes perceived by the Venetians as an attack on the environment and local cultural heritage rather than as a defence strategy. As Hayward states, aquapelagos:

are assemblages that come into being and wax and wane as climate patterns alter and as human socio-economic organisations, technologies, and/or the resources and trade systems they rely on, change and develop in these contexts. (2012a: 7)

Aquapelagos can certainly change, adapt or welcome innovations - after all, these processes are absolutely normal within every human community even if they manifest themselves in different times and ways - but their cultures can also become extinct. And aquapelagic assemblages such as the Venetian Lagoon are particularly at risk due to the effects that the Anthropocene is causing on marine environments because the increase in temperatures causes warming and sea level rise, the displacement of currents with consequent changes in biomass and biodiversity (Hayward, 2012b:3-2). These are all factors that lagoon fishers have been denouncing for years.

\section{Acqua alta - a recent phenomenon?}

During several fieldwork excursions in the Lagoon, fishers told me that everything has been changing in recent decades. The Lagoon has altered, especially its tides, which have new heights, unusual frequencies and intensities, higher speeds and different paths. Based on surveys of the tidal zero of Punta della Salute in Venice, statistics show that during the 1900 s the water level increased overall by about 25 centimetres, confirming the fishers' 
observations (Canestrelli, 2009: 69-76) ${ }^{6}$. If meteorological events are added to these phenomena (such as wind, rain, river floods) the regular tides can undergo significant variations and further incentivise high waters, as fishers well know ${ }^{7}$.

The 1.94 metre level reached by the 1966 flood is the highest ever recorded in the Lagoon, but it is not the maximum height that can theoretically be reached. In fact, a perfect coincidence of all factors leads to a possible estimated peak of over 3 metres, even if the probability of this happening is estimated to be once every 10,000 years (without taking into account predictions of the future sea level rises). In order to clarify the impact of high waters on inhabited areas, it is necessary to remember that with tides of 1.4 metres, $59 \%$ of the city is submerged, while 0.8 metres are sufficient to submerge the entrance to the Basilica of San Marco and its square. The last serious flood occurred on 12th November 2019 when the tide reached 1.87 metres. The data provided by the Centro Maree of the municipality of Venice (as well as data concerning the $29^{\text {th }}$ of October 2018 event, estimated at 1.56 metres) has been disputed by many inhabitants who claim that in reality the heights were greater. All Venetians have their own points of reference to estimate the heights of the tides: the steps of their house, the courtyard, the distance between flooring and shop windows, a particular mark on the wall etc. all of which are used to evaluate the actual level reached by the water. They are evaluations based on the habitual observation of the phenomenon and these evaluations are often considered more credible.

The Venetian acqua alta is not a recent problem. Based on a study of historical data carried out by the Venetian Centro Maree over a period of 1500 years, catastrophic floods similar to the events of 1966 and 2019 are estimated to occur every 150 years. In 589 A.D., for instance, Paolo Diacono wrote in his Historia Longobardorum about floods and of an unspecified life between water and land that characterises the special relationship between territory and inhabitants (Canestrelli, 2009: 69). Moreover, ancient local chronicles have reported stories of the worst tidal events. In the absence of scientific data which can demonstrate whether the frequency and extent of floods have really worsened over the centuries, we can turn to a study by the researcher Dario Camuffo (of the Italian National Research Council). His original approach to investigating the trend of Venetian tides used paintings of the Venetian landscape by Canaletto and Bellotto and Veronese. Observing the paintings, his research reveals that the green frame of the algae present along the canal banks is much lower than today and that the landing stairs on the Grand Canal of the palaces appear free from water (Camuffo et al, 2017: 73-86). Further iconographic evidence of the presence of acqua alta in the past can be found, for example, in a painting by the Venetian Vincenzo Chilone, dated 9th December 1825, where richly decorated gondolas are represented navigating the interior of St. Mark's Square (Figure 4). This not only shows us that high tides were a common phenomenon in the past but also demonstrates that it was not particularly feared and could also become an opportunity for wealthier people's enjoyment.

\footnotetext{
614 centimetres are attributed to the natural subsidence to which the lagoon is subject and about 11 to eustatism.

${ }^{7}$ It is important to remember that it was only from 1867 that the acqua alta phenomenon began to be recorded regularly using modern scientific methods. In fact, the current local tide levels conventionally refer to the Altimetric Network of the Kingdom of Italy of 1897. The tidal zero was established on the basis of the tidal surveys carried out at Punta della Salute (Venice) between 1885 and 1909. During the Second World War, the Military Geographic Institute decided to adopt another altimetric reference (zero), called Genoa 1942, which is $23.56 \mathrm{~cm}$ higher than the zero of 1897 . Currently all of Italy refers to zero IGM 1942, while both references are used in the Venetian Lagoon, but the tide heights refer exclusively to the tidal zero of 1897 . For further information on the subject see Città di Venezia (nd).
} 


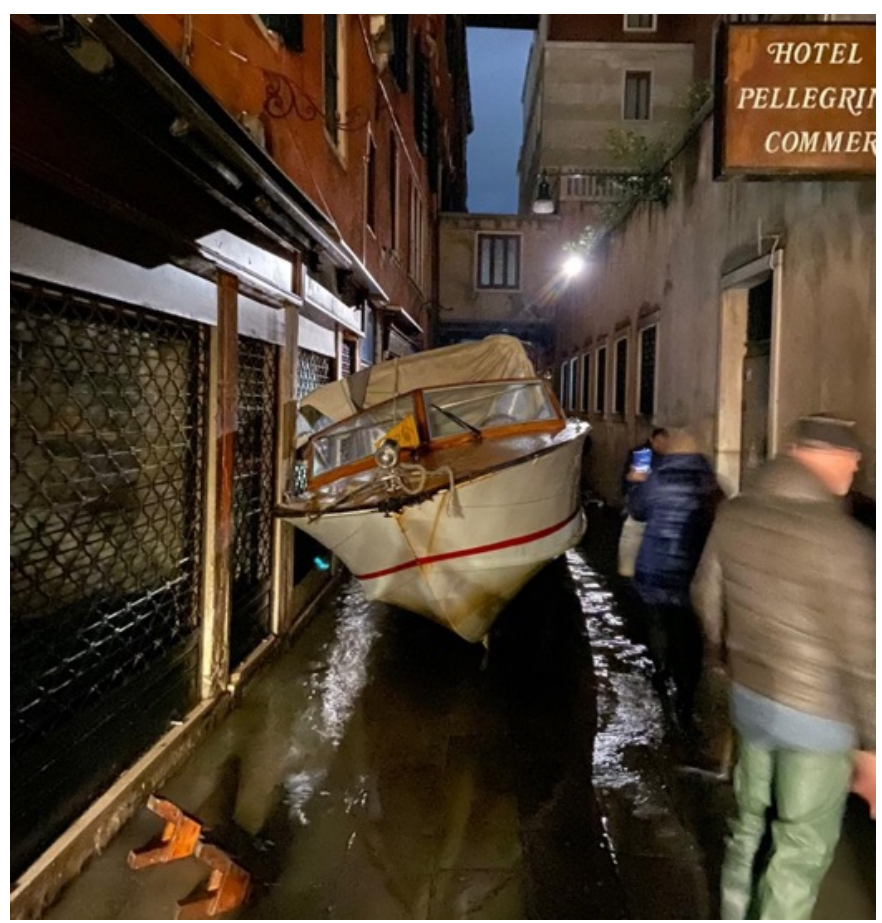

Figure 3 - an example of the consequences of the acqua alta event of November 12th 2019 (author's photo).

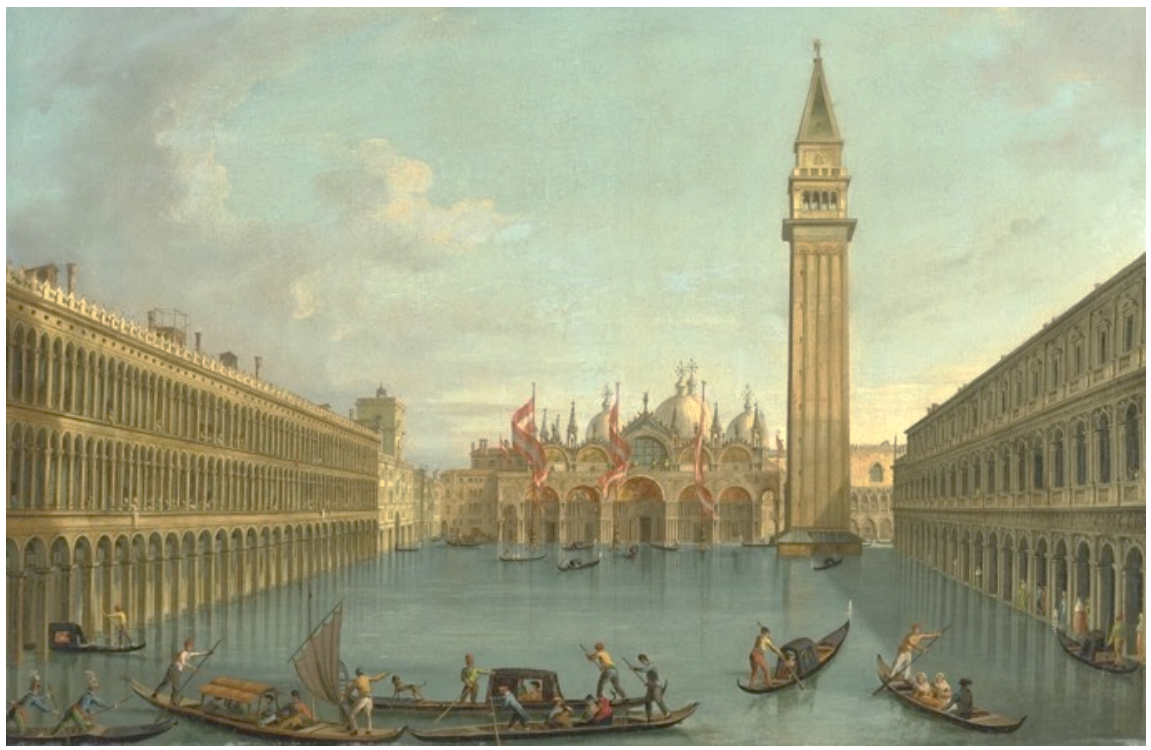

Figure 4 - 'The Plaza di San Marco, flooded', Vincenzo Chilone (1825). 
For fishers today, the acqua alta is a phenomenon that is both benevolent and evil at the same time, depending on how it manifests itself. As Antonio S., a fisher from Lido island mentioned to me during an interview in 2015, the acqua alta is useful and necessary because its action purifies the city:

Acqua alta is beneficial, it is good, because it cleans. There are no sewers in Venice, and the high water takes away all the dirt in the water and cleans the streets. This is why it is also good for disease. Because it takes everything away.

But the acqua alta can become treacherous, like sea waters, when it takes on a destructive dimension, overwhelming everything it encounters. It becomes water that is to be feared and that needs to be controlled. To demonstrate the contrast between the benevolent lagoon water and the dangerous marine water in this area we can note that there are many ritual practices of sacralisation and control of the Adriatic Sea but not for the Lagoon ${ }^{8}$.

IV. The fishers: forms of resilience between climate change, new tides and megainfrastructures

It is a fact that the phenomenon of high water has increased in the Venetian Lagoon in recent decades, both in frequency and in height. In the 21st Century, some scientists have linked this data to the global rise in sea levels. According to the latest projections of the IPCC (Intergovernmental Panel on Climate Change), ${ }^{9}$ the Earth's climate is warming at an unprecedented rate. This brings with it a rapid rise in sea levels, which the worst projections calculate to be between 0.75 and 1.95 metres by 2100 (IPCC, 2019).

While the fishers of the Lagoon do not associate the rising sea and lagoon water temperatures with the increased intensity of acqua alta events, they do see warming as a primary cause of the changing habits of fish and their reproductive cycles, the presence of new species in the Lagoon and the disappearance or decrease of native ones. A fisher named Angelo B. and his son, also a fisher, explained that:

The fish are changing, there are new fish and ours are disappearing. It is the fault of the crazy climate; the water is warmer and even the crabs shed their skin whenever they want while they used to have their season, which was always the same. Clams also 'throw' their eggs when they want because they feel that the water is always hot, there is no longer the cold that used to be, with winter ice. (2019).

Antonio S., a fisher from the island of Lido adds:

Now it's all full of blue crabs, American stuff, American crabs, they came with the ships and they had a good time here because it's hot now. And they are eating

\footnotetext{
${ }^{8}$ For example, the San Domenico ceremony in Chioggia and that of the Sposalizio (Marriage) with the Sea at the Lido inlet.

${ }^{9}$ In 1988 the United Nations founded the IPCC, but as Bruno Latour argues, not everyone accepts its creation in a positive way. Some Western media and public opinion interpret the IPCC as an attempt to dominate the planet by 'mad' scientists and present the chemistry of the upper atmosphere in a way that is a conspiracy against the American way of life, with the very concept of ecology perceived as an attack on humanity's inalienable right to modernise (Latour, 2015).
} 
our local crabs. They are destroying everything. Then there are the puffer fish, the barracudas, all stuff that isn't ours. ${ }^{10}$ (2020)

These observations are generally overlooked by natural scientists because - as anthropologist Deborah Bird Rose (2017) points out - they offer us only verifiable numbers and measurements, leaving out the variety of local worlds of knowledge that are dying out following climate change. While the experts, or rather the holders of scientific and technocentric knowledge, debate the origins and causes of the increase in floods, fishers provide different explanations. The relationship between human interventions and the tide has been clear to fishers for a long time. In the southern Lagoon, fishers have already experienced the serious consequences of the excavation of the Petroli Canal ${ }^{11}$ in 1969. They remember how the new canal raised the average height of the water throughout the southern basin. This is how Emilio Ballarin remembers the before and after of this invasive intervention on the Lagoon:

When I was a child and there were shoals, you could see a prato ['meadow'] emerging from the palùo ['swamp'] that reached the Euganean Hills [which are visible on the western horizon]. Now, when you see some seaweed rising, you say 'Oh my God! Look how dry it is! '. And the prati that were there before, what happened to them? All this has disappeared and consequently the fish have also disappeared. Here the Lagoon is less and less a lagoon. (interview 2019)

It is interesting to note that algae-covered seabeds that emerge at low tide are called prati by the fishers, a name taken from the terrestrial world to indicate what is instead below the surface of the water ${ }^{12}$. The use of this type of denomination makes us understand that the Lagoon represents a domestic environment for fishers and consequently it is not at all perceived as an alien, wild and dangerous space (characteristics that, instead, refer to the sea.

The construction of the Petroli Canal has made it impossible for fishers to practice some local fishing techniques that, as a consequence, have been definitively abandoned. ${ }^{13}$ Angelo Scarpo, an elderly fisher from Pelelstrina, told me in 2019 that the new canal forced local fishers to abandon fishing with seràge (large seine nets that were common at the time) in this area because the increase in the water level submerged them completely, even during low tide, and it was no longer possible to catch fish inside them. For all fishers, this example has offers a further warning about the dangers resulting from the alteration of the Lagoon's equilibrium. Digging new deep channels, Angelo explains, involves a redistribution and sometimes an increase in water flow. The excavation has transformed this canal into a sort of siphon capable of introducing a large amount of water into the Lagoon; the same effect

\footnotetext{
${ }^{10}$ Some of my long-time interlocutors often send me video footage of fish, crustaceans and algae that they have never seen before to substantiate their perceptions.

${ }^{11}$ The Petroli Canal is an artificial channel 15 metres deep that was dug to allow oil tankers to reach the Marghera petrochemical refineries directly through the Malamocco inlet.

${ }^{12}$ Leroi-Gourhan $(1977,2018)$ asserts that the names of things, places, plants and animals are humans' means of domesticating the environment and thus making it knowable and controllable. In the present case study, even what is hidden from our eyes under the surface of the water does not seem to be an exception. Manlio Cortelazzo, an Italian linguist who was among the first to study the names of marine features used by fishers in the Adriatic Sea, speculates that the deployment of names in the marine repertoire seems to come mainly from the larger lexicon that terrestrial names offer (1992: 62-83).

${ }^{13}$ Interview with A. Scarpa, 13th of November 2019, Pellestrina island.
} 
that fishers attribute to the excavation of the inlets to house the dams of the MOSE system. Consequently, we should not be surprised if we find widespread rejection and distrust for the new infrastructures among fishers. Such a reaction was also observed by Scaramelli (2019) in his research on two coastal areas in Turkey, where fishers and their families are struggling to maintain their livelihoods in transition because of recent ecological changes due to the creation of protected areas. In his case study, fishers, scientists and residents expressed contrasting moral perspectives on ecologies relating to infrastructures. By contesting the infrastructural refurbishment of delta environments, fishers link ecological change to livelihood concerns, scientists affirm a unique moral authority to create new habitats for selected species, while activists demand ecological justice within existing legal frameworks, all against the backdrop of a growing authoritarianism and economic crisis. The reading that Scaramelli offers takes into consideration the theory that political action linked to the construction of new infrastructures is not exclusively projected on animals, plants, soil, water flows, sediments, sandbanks, rocks and other non-human beings and materials. Rather, people make politics through them. Thanks to the moral ecological approach, she highlights the need for a pluralism of behavioural strategies in order to promote high levels of cooperation within groups and the complex dynamics of interactions between these strategies over time. In Venice, fishers, inhabitants and environmental associations also feel this need but they are ignored by those who have managed and currently manage the MOSE project.

If the Lagoon can be defined as an environment dominated by the water and where the water is its distinctive element, what really is the Lagoon? First of all, it should be made clear that what we observe today is not, objectively, a natural environment. This is because it is the result of centuries of human interventions aimed at its conservation. If this had not been done, the Lagoon would today be filled in or overwhelmed by the sea. What we observe is a landscape erroneously perceived as shaped exclusively by natural elements but, in actuality, shaped by humans. It is, thereby, an anthropised space. The anthropisation of the Lagoon territory took place not only by means of conservation work but also by means of economic activities related to fishing such as the presence of fishing nets and tools, the construction of cabanas (fishing huts on stilts), mussel-farming, the briccole (the wooden poles that indicate the navigable canals) and the typical votive capitals mounted on briccole or on stilts. Venetian fishers perceive the Lagoon as a domesticated space, an extension of the emerging lands, of which they have very accurate mind maps. They equate the Lagoon territory to a rich 'countryside', meaning by this term a place that is safe, protected and rich in resources. This is how a fisherman from Chioggia interviewed in 2018 described the Lagoon:

For us, the Lagoon is like the countryside for the farmers. You can't get lost even if you travel at night and with fog. There is no danger of going overboard. When I was a little boy everything was born here, now they have ruined it.

As we can see from this short passage, for the fisher, the Lagoon is above all, a well-known territory in all its visible and invisible parts, even if they are submerged.$^{14}$ Another interesting aspect emerges when fishers try to describe the Lagoon. Some fishers describe it as a complex organism that is, in many respects, similar to a human. This perception does not represent animism, recognising that water is a more powerful organism than humans, but posits that as a complex organism the Lagoon can become sick and unwell, just like a human can. The

\footnotetext{
${ }^{14}$ This reminds us of what Maxwell writes concerning the seas. He explains that seas "are known (as are the lands) in and through processes of embodiment: they are felt, attuned to, personified, negotiated with and incorporated, as much as they are charted, quantified and overcome" (2012: 22).
} 
fishers perceive that the disease manifests itself as an imbalance between the species that inhabit this particular ecosystem. For example, the aquatic environment is sick when there is too much algae, or too many jellyfish:

She [the Lagoon] is like us, she gets sick. When there are too many jellyfish or too much algae it means that the Lagoon is sick. We have to wait; not go fishing for a while, or fish little and only certain things, and so the Lagoon heals (Gianfranco V., interview 2017).

Such problems are never perceived as the fault of human fishing activities but of the ecosystem which has become ill. We just need to wait, without intervening, and everything will recover by itself. During an interview in 2015, Amalia B., a woman from Pellestrina, complained about the institutions:

They always blame the fishermen, but nothing is true. The ecosystem brings some things in certain periods and others in another. It adjusts itself. Years ago, even the crabs were gone, and now they are back without the fishermen doing anything. This is because the Lagoon regulates itself.

In the words of this woman, the daughter, wife and mother of fishermen, the scarcity of a species should not be attributed to overfishing but is due to the self-regulating ecosystem. Traditional local knowledge suggests (more or less consciously) that a good balance of the ecosystem corresponds to a good balance between the different species that live together. The small fishers of the Lagoon appear, in certain respects, to be aware of the need for exchanges between living beings to continue living (or surviving) in the interstices of capitalism. At the same time, it is a vision that should not be idealised, because sometimes it tends to be predominantly utilitarian: a healthy environment corresponds to an environment rich in resources, and an environment rich in resources allows profitable fishing and consequently good profits. There is no real ecological conscience among fishers and the view of the water as a large organism of different species in balance with each other is used to justify the excessive exploitation of a single resource by the fishers.

The close relationship with water is not an exclusive concern for fishers but, according to the geographer Cavallo, has to be extended to all the inhabitants of the Lagoon. It is possible to state that the Lagoon is characterised by a kind of life which is essentially aquatic and insular; this implies a very close relationship between the inhabitants and the water, which becomes the privileged space for the daily practices of the population. Cavallo contends that the intense symbiotic relationship between humans and water is the primarily characteristic of Lagoon dwellers, giving them a sense of identity that transforms a person into a 'Venetian' (2015: 125-140). To give an example, knowing how to row and steer a boat was once the only way to access the Lagoon, which therefore remained a space reserved solely for the inhabitants. It should not be overlooked that every society develops multiple habits that relate to water, a special element that, like air, has no boundaries and does not have its own defined shape (for example, unlike solids, fluids can adapt their shape to containment structures - natural, such as riverbeds, or artificial, such as dams). Furthermore, as Strang (2004) points out, water involves the sphere of deeper emotionality much more than the other elements. In her study of the aquatic environment and the meaning of water, she highlights that it can stimulate affective responses in many different cultural contexts. In her opinion, human sensory experience concerning water qualities is to some degree universal, and this commonality doubtlessly contributes to the recurrent themes of meaning encoded 
in water in many different societies and also leads to specific articulations unique to particular physical and cultural times and spaces (ibid: 49).

If human sensory experience is formed in developmental engagement with a particular sociocultural and physical context (mediated by cultural practices and interpreted in the light of cultural beliefs and values), as in regard to the specific case of the Venetian Lagoon, the relationship with the aquatic environment and its meaning sums up the real characterising traits of 'Venetianness'. Consequently, it is pertinent to investigate if in Venice, this characteristic is mainly due to the city's peculiar aquatic dimension or if there is also something else. To better understand individual perceptions and emotional relationships, it is pertinent to consider the concept of hydrophila. This term emphasises the attraction of aquatic environments (such as rivers, lakes, lagoons or coasts) for humans compared to other environments without the presence of water on the surface (Vallerani, 2019: 108-110). In the opinion of Vallerani, hydrophila:

could be defined as an ancestral perception concerning the aesthetic experience that begins with physical stimulation of the senses, that is the physiological mechanism of sight, smell and hearing, and ends in moods, emotions and meanings (2020: 59).

According to environmental psychology, the lifestyle of the Venetians would represent a form of embodiment between the inhabitants and the water, triggering a feeling of psychophysical well-being in the inhabitants (Pitt, 2018). In fact, speaking with those born and living in Venice it is common to hear comments regarding the lack of proximity and view of the water after a stay outside the city, whether it is a holiday, a business trip or a simple visit to Mestre on the Venetian mainland. Nevertheless, nowadays this symbiotic relationship is changing: the water spaces - which once facilitated a unique and non-exportable lifestyle have become romanticised in order to feed an increasingly trivialised touristic imaginary, undergoing a gentrification process in itself (Vianello, 2020: 135).

\section{The MOSE machine: a technocentric environmental vision}

The event of the 4 th of November 1966, when the tide reached 1.94 metres, was a significant one in the life of the Lagoon and its inhabitants. From this date, a painstaking process was undertaken in search of possible solutions to protect the inhabited areas from submersion. It was from this moment that, for the first time, people began to consider the need to protect inhabited areas by subjecting the Lagoon to ambitious flood protection works of a purely technical type. This process has involved many partners, both public and private, but has neglected the opinion of locals and of those who work with and on the water, such as fishers.

What is commonly referred to as the MOSE is an impressive hydraulic engineering project that aims to protect the entire Lagoon ecosystem from high tides. In summary, the project consists of a system of 78 mobile gates positioned in the inlets, tasked with isolating the Lagoon from the sea during exceptionally high tides. The design and construction were entrusted by the Italian State in a joint concession to a group of companies called by the evocative and ambitious name of Consorzio Venezia Nuova ('New Venice Consortium') $(\mathrm{CVN})$. According to many of my interviewees, the choice to establish an effective monopoly of the process carried the inherent risk of creating a vast mechanism of corruption. On June 4th, 2014, these predictions came true and the Finance Police arrested 35 people and put another 100 under investigation for illegal party financing, tax fraud and false billing 
(Amadori et al, 2014). Opponents of the project rely on this legal matter to demonstrate how support for the creation of the MOSE was effectively bought. One of the interviewees told me that it was normal for the CVN to bribe opponents in various ways to obtain their consent or silence. In this regard, he recounts his personal experience: being the son of one of the major opponents to the MOSE project, a well-known and respected person in the city, the director of the CVN commissioned him to carry expensive research project over the 1990s with the aim of winning the support of his parent, but which remained unused and buried in a drawer. A further example of the means of persuasion used to acquire consensus is represented by what happened to one of the engineers who had carried out an interesting project competing with the MOSE. The project was rejected by the examining commission, but, in implicit exchange, his children were later hired by the CVN. ${ }^{15}$

From 1st of December 2014 the CVN was placed under extraordinary administration (Fazzino, 2014). In the intervening period nothing seems to have changed for the Lagoon or for the Venetians: the works were suspended or extremely slowed down, malfunctions followed one after another, and nothing changed in terms of transparency and communication. According to the commissioners, the construction works were actually proceeding regularly, but were not visible as the works took place exclusively underwater. The engineers continued to defend their work by stating that it was perfectly compatible with the Lagoon and blamed the executors of the work for the defects and the problems encountered over time.

After the last serious flood that devastated the city and the Lagoon islands, in November 2019, when the resonance of the devastation that occurred in Venice spread worldwide, the authorities found themselves forced to take action. Following numerous new lifting tests that took place in optimal weather conditions, and which still presented malfunctions, on 3 rd of October 2020, with a tide forecast between 130 and 135 centimetres, the MOSE system has its real first test $^{16}$ (Figure 5 ). The result was a success. While at sea the tide reached 130 centimetres accompanied by strong wind, it did not exceed 71 centimetres in the Lagoon where the water stayed calm and lake-like and the city remained dry ${ }^{17}$. During this first true experiment, a procession of people, Venetians and non-Venetians alike, crowded the breakwaters - despite the bad weather - to watch, take photos and videos (Figure 6). Based on comments heard, the fear felt most was linked to the possible failure of the mechanism and the consequent transformation of a high water level into a violent wave that could overwhelm Venice. After fifty years of proposals, alternative projects and conflicts (and floods), many Venetians consider the structure to be a serious risk for the city. There is widespread anger and anxiety about what may happen in the future in the event that the MOSE malfunctions, despite the success of the 3rd of October 2020. Observers made comments such as "today it held up, but it's all rust underneath, what will happen next time it goes into operation?"

As D'Souza states in his studies on river environments in Asia, the Venetians' reaction is not anomalous. On the basis of his research, he contends that the construction of any giant mega-infrastructural project will invariably produce environmental and social anxieties and resentments, especially when the new infrastructures intervene in historically evolved local livelihood strategies. Environmental resentment is manifested above all when people have

\footnotetext{
${ }^{15}$ The sons refused to give me any interview or statement on the matter and asked for anonymity.

${ }^{16}$ During the writing of this article, the MOSE has been tested on other occasions and has gone into operation during the peak high tides.

${ }^{17}$ Throughout this first, test port companies reported that access was blocked for 9 consecutive hours on the same day, leaving 14 ships waiting and asking for urgent attention.
} 
previously experienced similar situations, such as the reaction observed in the Lagoon with the negative experience of the Petroli Canal (D'Souza, 2016: 241).

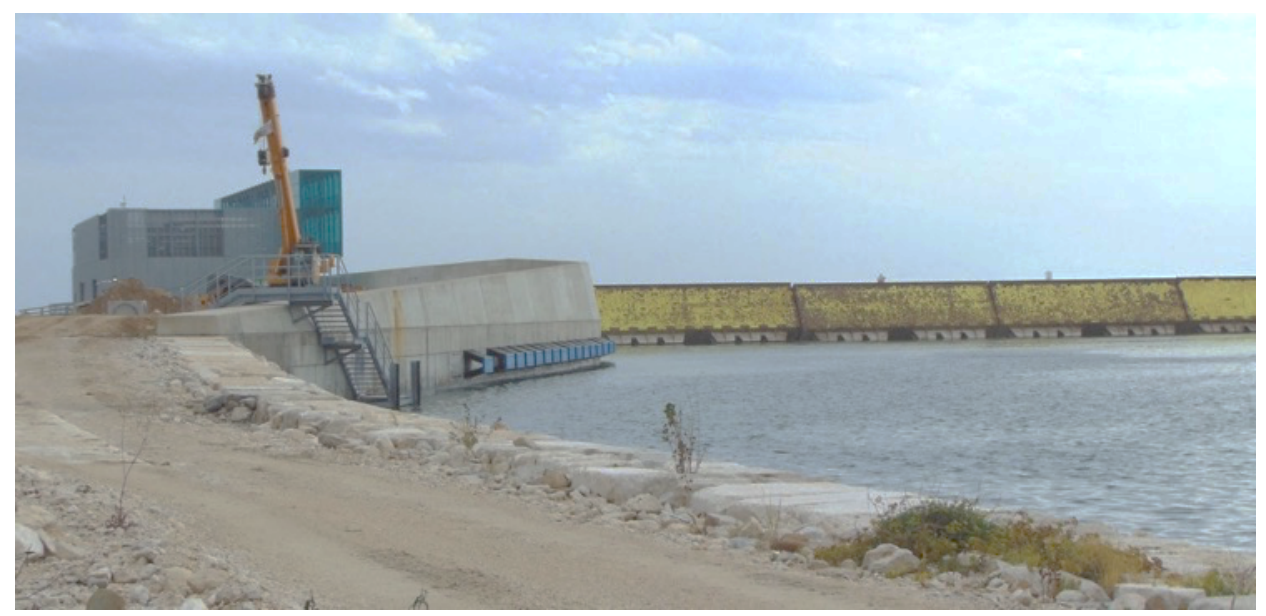

Figure 5-3rd October 2020: the MOSE in a raised and working position (author's photo).

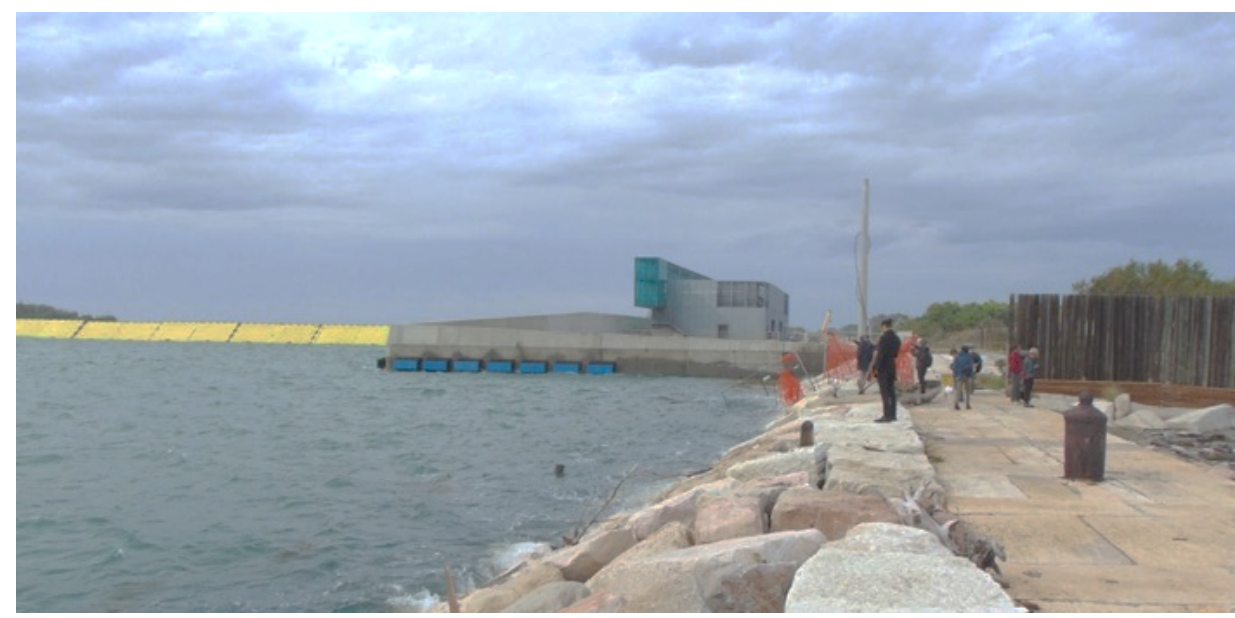

Figure 6 - 3rd October 2020: people standing on the dyke of Malamocco inlet (author's photo).

Many people have expressed anger because the 'authorities' (referring to politicians, engineers and other institutional figures in general - who are often defined as thieves and cheaters) found themselves forced into action because they were under the spotlight of the world media. The MOSE went into operation within less than a year, which is equivalent to an admission of deliberate delay in completing this mega-work. Finally, some of those who witnessed the historic moment blamed environmental movements (perceived as exclusively adhering to the political left) of slowing down the construction work with their oppositional actions. The main opposition committee, No MOSE today (now merged with No Grandi Navi 
['No Big Ships'] $)^{18}$, speaks of the success as ephemeral, as the closure of the gates is planned to start from tides of 110 centimetres when it is fully operative, even if the closure is currently decided by the CVN in response to specific conditions. The city will still be partially flooded by lower tides, which are more frequent. Furthermore, opponents maintain that it remains an expensive project in its maintenance and activation ${ }^{19}$ and has caused a lot of damage to the ecosystem, starting from the change in the circulation of natural currents. The committee also insists on the danger of failure of the gate system due to the resonance phenomenon. ${ }^{20}$ In practice, the fears of the inhabitants could come true, with the possibility of a violent wave sweeping through everything in the unfortunate case that a gate gives way. ${ }^{21}$ These complaints are also shared by many researchers of hydraulic engineering, such as the architect Stefano Boato, professor of architecture at the University of Venice, and the engineer Luigi D'Alpaos, professor of Hydraulics at the University of Padua. D'Alpaos, relying on advanced mathematical modelling, and sharing several of Boato's positions, asserts that the objectives of modern humans cannot be reconciled with Lagoon protection (D'Alpaos, 2019).

While the MOSE project was designed in the 1980s, and the preliminary project was presented in 1989, it originated in similar projects from the early 1970 . For this reason, many opponents consider it outmoded, in that the engineers started from the old conception that the environment must adapt itself to the conservation works and not the opposite; that is, that an engineering project must be respectful of the environment in which it will operate. This perspective is also shared by scholars who deal with water governance, who have pointed out that the vulnerability of a water environment is not a given, but it is largely due to the results of politics and an engineering approach to water control that has predominated over the last 150 years (Wesselink et al, 2015). A type of philosophy of engineering has emerged whereby nature must necessarily adapt to the human technology.

Throughout the history of the MOSE, we find very few Venetians among the engineers. We can however find some Venetians among those involved with projects which have been rejected. Some Venetian engineers were hired for a short time but without any major responsibilities. During the research, it was very difficult to secure meetings with these professionals. When this was possible, I met people who did not seem to understand the meaning of my questions. During the only two meetings obtained I observed a common denominator among them: an attitude of derision towards the fishers and their associates. This attitude was also shared by some US engineers who were present. The 'rigidity' that can characterise the so-called 'hard' sciences was evident in a particular mindset that suggested their orientation to environmental vision which is instrumental to humans. The engineers' technocentrism evinces a belief that environmental control is feasible through sophisticated technology management, in contrast to the humanistic approach that emphasises the importance of individuals, society and local culture, supported by residents and fishers

\footnotetext{
${ }^{18}$ For further information see the No Grandi Navi website.

${ }^{19}$ It has been widely reported that it will cost 100 million euros per, a figure never confirmed but never denied.

${ }^{20}$ Resonance describes the physical phenomenon in which the natural oscillatory movements multiply their amplitude due to the effects of wave motion (D'Alpaos, 2019: 38). If the vibration caused by the waves enters into resonance with the natural vibration of the MOSE dams' structure it can cause them to collapse.

${ }^{21}$ This potential issue made it harder to accept the project, even for some right-wingers (who are generally more favourable towards the MOSE project). This fear was also felt by the project's opponents (who are generally left leaning).
} 
(Gallino, 2007). Despite the contributions to interdisciplinary research necessary to address the problems related to the Anthropocene in depth, as stated by Ingold and Simonetti, a gap persists between the natural sciences and the human sciences. The former tends to focus more on the material aspects of environmental change - by analysing phenomena in a 'rigid' manner as befits a 'hard' science - while the latter appear 'softer', that is, more inclined to attend to the ways in which humans attach importance to them (Ingold and Simonetti, 2018). In the course of my fieldwork, the adjective 'rigid' was used unknowingly more than once, including by some interviewees who worked for the CVN. A marine archaeologist who has been excavating in the inlets on behalf of CVN for ten years who requested anonymity explained in 2019:

The CVN is rigid just like the rigid modern materials used in the MOSE project today, even if the CVN has now taken on a lower profile following the 2104 scandal.

This attitude, he adds, was also reflected in the character and human qualities of people in this sector. Referring to Venice, he explains that he has always been surprised by how a concept of rigidity has predominated in modern projects, guaranteed by the technology of the materials, which contrasts with the previous 1,500 years of history, during which elasticity has always been the prevailing concept, as it is perfectly suited to the Lagoon environment and its movements. This focus is close to that described by Ingold and Simonetti concerning the use of hydraulic concrete, which gave engineers the illusion of having somehow managed to have a form of lasting control over nature.

Another informant who collaborated with the Consortium, a researcher from the Italian National Research Council, also describes CVN personnel as 'rigid' people in the sense that they had a brusque and doctrinaire attitude which sometimes made them very arrogant. This feature is confirmed by exponents of local politics who complain of an attitude of superiority whenever public comparisons were requested or when opinions of citizens were expressed. Gianni G., a former Venetian city councillor says:

It was like hitting a wall. They ignored you, they never answered, they always wanted to be right. They were very hard on everyone.

The then mayor of Venice Massimo Cacciari (a philosophy professor at the University of Venice) ran into this wall in 2005 when he appointed a commission of experts to carry out a comparative evaluation of five different flood mitigation projects, all of which were rejected. In this evaluation, the MOSE ranked in the last place in each of the scenarios examined. The most positively evaluated proposal was for a partial closure projects of the inlets through the use of so-called self-sinking and removable port-ships in the summer period ${ }^{22}$. The secondbest evaluation went to to the gravity gates and in third place was a closure project with mobile inflatable rubber dams similar to the one realised in Rotterdam (Danella, 2018).

On the basis of the testimonies collected, today the importance of a new, 'soft', approach to the management of the conservation works is evident. But in the management of the MOSE, a top-down approach has been established from the beginning. The engineers and technicians have presented themselves as the bearers of a rigid technocentric environmental vision which neglects local knowledge. This attitude is widespread internationally. For this

\footnotetext{
${ }^{22}$ This was the project presented by the team led by Venetian engineer whose children were subsequently hired by the CVN.
} 
reason, a number of anthropologists who study aquatic environments and are well-placed to mediate between the different disciplines involved in major environmental engineering projects have stressed the need for an in-depth understanding of the lived experience of inhabitants (Krause, 2017).

\section{The MOSE and fishers' traditional ecological knowledge}

The rigid technocentric approach has neglected all other opinions, knowledge and historical specificities and has regarded local economic factors as expendable. The fishers' local knowledge of the environment and the tides, resulting from direct experience, has not been listened to, despite many complaints by fishers and reports from trade associations. The fishers' knowledge has been neglected by public institutions in favour of technical and engineering skills, that is to say, in favour of the expert and institutional knowledge, which has been adjudged as of greater importance. According to fishers' point of view, the interventions involved in the construction of the MOSE in the Lagoon's inlets have, among other anthropogenic interventions, produced major changes in the Lagoon ecosystem. To give one example, in the aftermath of the last serious flood on the 12th of November 2019, the fishers were not too surprised by what happened. Many of them predict that similar events could repeat themselves in the future, precisely because of the excavations carried out in the inlets to house the MOSE. These excavations have made the three inlets that connect the sea and the Lagoon deeper and narrower. Because of this, a greater amount of water passes with greater speed during peak tides than in the pre-MOSE time. Fishers have repeatedly denounced - without any success - the variations in the circulation of currents, which have disappeared from some areas where they were previously present only to appear strongly in areas where they did not exist, distorting the usual paths of the currents and the fishers' mental maps of the Lagoon. For this reason, some of the usual fishing areas have been abandoned and replaced, when possible, with completely new ones (requiring new knowledge). In the Venetian Lagoon, fishers have conventionally had preferential access to particular territories as a result of a communally agreed division of the waters in which to fish. For example, the fishers of the southern Lagoon do not fish in the central or northern parts, which instead pertain to those who live in these areas. This practice, functional in avoiding conflicts for access to resources between fishers in the Lagoon, makes it even more difficult to identify new fishing areas in a constantly changing territory (Vianello, 2017).

The environmental impact of engineering work to protect Venice from peak tides has also been noted by non-professional fishers who frequent the breakwaters, who have reported hydrodynamic upheavals. One of these, Antonio S., has reported severe disruptions:

They have changed the currents; they have already changed all the seabed. You can no longer fish. The marine flora and fauna that reproduce on the seabed, which has been created over the centuries, seabeds that were inhabited by lobsters, sea bass, crabs and mussels, have all disappeared. And they were returning [after the seaweed problems in the early 200os] and now they are all gone. They threw stones, changed the currents. The current is much stronger now and takes you away... The breakwaters have been narrowed, and the current is directed like a highway and therefore destroyed the seabed, dug holes. (interview, 2016)

While fishers were not too surprised by what happened on 12th November 2019, technicalscientific experts from the CVN released many statements to the media emphasising the 
exceptional nature of what happened (e.g. Rapisarda, 2019; ISPRA, 2020). This disparity of attitudes closely resembles what Marita and Suzuki (2019) described in a study on the Chao Phraya river delta in Bangkok. The two anthropologists note that following a strong flood resulting from a modest amount of rain, those who were taken by surprise were also, in this case, the experts in hydraulic engineering. The local population, on the other hand, had been able to see and interpret the relationships between the environment and the new infrastructures built (in this case a dam) and were not particularly impressed.

According to the fishers, lagoon biologists and institutions such as ISPRA ${ }^{23}$ or CNR-Ismar $^{24}$ that work with and within the Lagoon do not understand what the Lagoon really is and, consequently, blame the fishers for every problem. As a result, they have intervened by imposing new rules and regulations on fishers. But fishers consider these rules useless and harmful. In their opinion, human interventions in the environment are always problematic and they perceive an altered balance as a sort of punishment resulting from its profanation. For this reason, many fishers blame the MOSE, a man-made product, as the main culprit in the progressive death of the Lagoon. This would be the punishment that humans deserve for having dared to alter an organism larger and more complex than us (Dalla Bernardina, 2010).

Interventionist engineering and everything that follows from it appears as what Latour (2015) terms a "delirium" in which it is believed that in order to repair damage caused in the past, it is necessary to engage in further "megalomania" by intervening in an increasingly massive manner on the environment. As Latour writes:

Because the threats are so severe and the transformations we have made to the planet are so radical, they [the geoengineers] have proposed to 'take the whole Earth system head on', considering it as a vast machine that has stopped functioning properly because it has not been monitored sufficiently. So here they are, seized by a new desire for total domination over a nature always conceived as recalcitrant and wild. $(2015: 33)^{25}$

MOSE is premised on a perception of nature as recalcitrant and in need of control. As we have seen, the construction of this mega-infrastructure required a whole series of interventions of increasing impact, transforming a project that was supposed to protect the Lagoon and the city into a "delirium," ${ }^{26}$ distorting a particular environment in order to transform it into something else that resembles, to use the fishers' words, an arm of the sea rather than the original hybrid environment.

\section{Conclusion}

The climate is changing, and Venice will have to start taking this into account due to the expected rise in sea levels that will impact the Lagoon. Rather than committing to countering what is the great challenge of our time, humans, with their neglect of the environment, are contributing to the acceleration of the process. Western societies in particular, seem

\footnotetext{
23 The Istituto Superiore per la Protezione e la Ricerca Ambientale ('the Higher Institute for Environmental Protection and Research').

${ }^{24}$ The Italian National Research Council's Instituto delle Scienze Marine ('Institute of Marine Science').

${ }^{25}$ Translation by the author from the text of the Italian version.

${ }^{26}$ A new island was even built in the Lido inlet.
} 
increasingly deprived of cognitive faculties regarding their ability to interact with their environments (Pineau, 2020). We are forgetting that it is inevitable that nature's metasystem will take its course, ignoring mankind, and that a future for planet Earth certainly exists, but it may be one without us. Our memory as human beings is based on a subjective and anthropocentric principle (in practice, on our own history), which is however, trifling within the timeline marked by geological phases ${ }^{27}$. This makes it difficult for us to study the changes of the Anthropocene over the long term because we have hardly any concrete data from the past to deal with.

In this context, with regard to interventions to safeguard the Lagoon, there is an open conflict of opinions. This type of conflict is not limited only to the geographical area under consideration today but is common to many other similar situations. In the national and international political arena, the battle between scientific knowledge (or rather its application in a technical and engineering) and local knowledge is key; and in the local the former has indisputably overridden the latter. This follows a type of belief according to which the extraordinary powers of humanity, identified with scientific and engineering knowledge, can solve any current problem of future crisis (as stated by Donna Haraway who coined the expression "technocratic geoengineering" to indicate the spread of this attitude in 2016). Scientists currently tend to present themselves as quantitative analysts and consequently limit their analyses to the material aspects of the phenomenon, excluding any ethical considerations (Descola and Palsson, 2010). They have become the holders of knowledge and are perceived as being of a 'higher' level than ordinary people (like the fishers in our case). The result is that the local dimension is neglected and hidden (Tsing et al, 2019). This is the case with the MOSE in Venice, where fishers - whose life paths form a set of heterogeneous practices, but which nowadays include the idea of margin and adaptation - have asked political authorities and institutions to be able to express their opinion but without any success.

Yesterday, as today, in the hard-fought and complex issue of the MOSE machine, the great absentees continue to be not only local knowledge, but also all the organisms, plants or animals that live in the Lagoon alongside humans. They contribute to the ecological balance of the Lagoon without ever being seriously considered. We have to remember that a good ecological balance corresponds to a good economic balance because a healthy Lagoon is also a Lagoon rich in resources for all those who live in it, including humans. This is a concept known to most of the fishers, especially the older ones, but is neglected by technical knowledge. To get out of this impasse, Scaramelli (2019) offers the notion of a moral ecology of infrastructure, theorising infrastructure and ecology as inseparable, rather than opposed. In his use of the term, moral ecologies are evaluations of justice and motivations for action that affect the relationships between humans and non-humans. What is certain is that today we require a new interdisciplinary approach to environmental issues which finally takes into account the humanistic aspects that are so often overlooked, but which can help us to understand, and perhaps overcome, the conflicts between the parties.

\footnotetext{
${ }^{27}$ We can re-read the history of the planet to remember extreme events and mass extinctions, or we can reflect on the stories of floods and depopulation of entire regions settled in the collective consciousness in the form of myths and legends (Galtarossa and Genovese, 2016).
} 


\section{Vianello - MOSE machine}

\section{BIBLIOGRAPHY}

Alliegro, E.V (2019) 'Antropologia dell'ambiente in crisi: “Manifesto per gli studi”, in Bonato, L (ed) Antropologia culturale, Milano: McGraw Hill: 333-339

Amadori, G, Andolfatto, M, and Dianese, M (2014) MOSE: la retata storica, Venezia: Nuovadimensione

Bird Rose, D (2017) 'Shimmer: "when all you love Is being trashed”', in Tsing, A, Swanson, H.A, Gan, E and Bubandt, N (eds) Arts of living on a damaged planet: ghosts and monsters of the Anthropocene, Minneapolis: University of Minnesota Press: G51-G63

Bonesso, G (2004) 'Granchi in laguna: la produzione delle moéche a Burano', la Ricerca folklorica n42: 5-26

Breda, N (2012) 'Antropologia dell'ambiente', in Bonato, L (ed) Antropologia culturale, Milano: McGraw Hill: 320-324

Camuffo, D et al (2017) 'A novel proxy and the sea level rise in Venice, Italy, from 1350 to 2014', Climatic Change v143: 73-86

Canestrelli, P (2009) 'Venezia, le “acque alte”, Quaderni di Insula s.p.a. n4: 69-76

Caniato, G, Turri, E and Zanetti, M (1995) La laguna di Venezia, Venezia-Verona: UNESCOCierre Edizioni

Cavallo, F.L (2015) 'Laguna, dispute territoriali e movimenti sociali a Venezia', Rivista geografica italiana v123: 125-140

Città di Venezia (nd) 'Riferimenti altimetrici': https://www.comune.venezia. it/it/content/riferimenti-altimetrici - accessed 16th February 2021

Cortelazzo, M (1992) 'Il lessico dei dialetti lagunari', La laguna v2: 62-83

D’Alpaos, L (2019) SOS laguna: salviamo Venezia e la sua laguna dai prenditori ingordi e politici senz'anima, Venezia: Mare di Carta

D’Souza, R (2016) 'Pulses against volumes: trans-boundary rivers and Pan-Asian connectivity' in Ganguly, S and Stool Farell, K (eds) Heading east: the dynamics of security, trade, and environment between India and Southeast Asia, New Delhi: Oxford University Press: 240-253

Dalla Bernardina, S (2010) 'Les invasions biologiques sous le regard des sciences de l'homme', in Barbault, R and Atramentowicz, M (eds) Les invasions biologiques, une question de natures et de sociétés, Versailles: Editions Quae: 65-108

Danella, A (2018) 'Venezia, progetto MOSE: la vera alternativa', Eddyburg 3oth January: https://www.eddyburg.it/2018/o1/venezia-progetto-mose-la-vera.html - accessed February 2021 
Descola, P and Palsson, G (2003) Nature and society: anthropological perspectives, LondonNew York: Routledge

Ellis, A, Tony, E and Bochner P (2010) 'Autoethnography: an overview', Forum Qualitative Sozialforschung v12 n1: https://www.qualitative-research.net/ - accessed 24th September 2020

Farinelli, M.A (2021) 'The impeded archipelago of Corsica and Sardinia', Island Studies Journal (forthcoming) published ahead of print:

https://islandstudies.ca/sites/default/files/ISJFarinelliSardiniaCorsicaImpededArchipelago. pdf - accessed 26th February 2021

Favaro, C and Vallerani, F (2019) 'Paesaggi d'acqua e idrofilia: luoghi, letteratura percezioni tra geografia letteraria e coscienza ecologica', Bollettino della Società Geografica Italiana n14 2(1): 59-72

Fazzino, E (2014) 'Scandalo Mose a Venezia, la corruzione in Italia persiste e scoraggia gli investitori esteri', Il Sole 24 ore May 5th: https://st.ilsole24ore.com/art/notizie/2014-0605/scandalo-mose-venezia-corruzione-italia-persiste-e-scoraggia-investitori-esteri-

144510.shtml?uuid=ABWAPKOB - accessed 24th February 2021

Fleury, C (2016) 'The island/sea/territory relationship: towards a broader and three dimensional view of the aquapelagic assemblage', Shima: The International Journal of Research into Island Cultures, v7 n1: 1-13

Gallino, L (2007) Tecnologia e democrazia: conoscenze tecniche e scientifiche come beni pubblici, Torino: Einaudi Editore

Galtarossa, M and Genovese L (2016) Acque amiche, acque nemiche: una storia di disastri e di quotidiana convivenza, Roma: Croma Edizioni

Ghetti, P.F (1990) Pesci molluschi e crostacei della laguna di Venezia: risorse ittiche e ambiente lagunare tra storia e innovazione, Venezia: Cicero Editore: 13-29

Godard, O (1992) 'L'environnement, une polysémie sous-exploitée', in Jollivet, M (ed) Sciences de la nature, sciences de la société: les passeurs de frontiers, Paris: CNRS Edition: 337345

Hayward, P (2012a) 'Aquapelagos and aquapelagic assemblages' (2012) Shima: The International Journal of Research into Island Cultures v6 n1: 1-10

Hayward, P (2012b) 'The constitution of assemblages and the aquapelagality of Haida Gwaii', Shima: The International Journal of Research into Island Cultures, v6n2: 1-14

Hewes, G.W (1948) 'The rubric "fishing and fisheries”, America Anthropologist v5o n2: 238246

Guerrin, C, Muxart, T (1989) 'Dur! Dur! La polysémie des concepts dans l'entreprise interdisciplinaire', in Mathieu, N et Jollivet M (eds) Du rural à l'environnement: la question de la nature aujourd'hui, Paris: Éditions Epi: 71-80 
Ingold, T (2016) Ecologia della cultura, Milano: Meltemi Editore

Ingold, T (2020) Siamo linee: per un'ecologia delle relazioni sociali, Roma: Treccani

Ingold, T and Simonetti, C (2018) 'Ice and concrete: solid fluids of environmental change', Journal of Contemporary Archaeology v5 n1: 19-31

IPCC (2019) 'IPCC special report on the ocean and cryosphere in a changing climate': https://www.ipcc.ch/srocc/ - accessed $31^{\text {st }}$ December 2019

ISPRA (2020) 'Venezia, 2019 anno record di eventi estremi: Focus sull'acqua alta del 12 novembre', ISPRA: https://www.isprambiente.gov.it/it/archivio/notizie-e-novitanormative/notizie-ispra/2020/o6/venezia-2019-anno-record-di-eventi-estremi-focussullacqua-alta-del-12-novembre - accessed 18th February 2021

Jonas, H (2009) Il principio di responsabilità: un'etica per la civiltà tecnologica, Torino: Einaudi

La redazione (2020) 'No Nav, Mose: 'risultati effimeri': comunità portuale- attività sospese sabato per 9 ore, Veneziatoday: https://www.veneziatoday.it/ - accessed 14th October 2020

Lahiri-Dutt, K (2014) 'Beyond the water-land binary in geography: water/lands of Bengal revisioning hybridity', ACME: An International E-Journal for Critical Geographies v13 n3: 505529

Lai, F (2020) Antropocene: per un'antropologia dei mutamenti socioambientali, Firenze: Editpress

Latour, B (2015) Face à Gaia: huit conférences sur le nouveau régime climatique, Paris: La Decouverte

Leroi-Gourhan, A (2018) Il gesto e la parola: Volume 1 tecnica e linguaggio, Milano: Mimesis

Marinelli. M (forthcoming, 2021) 'The impeded archipelago of Corsica and Sardinia', Island Studies Journal - published ahead of print online:

https://islandstudies.ca/sites/default/files/ISJFarinelliSardiniaCorsicaImpededArchipelago. pdf - accessed 26th February 2021

Maxwell, I (2012) ‘Seas as places: towards a maritime chorography', Shima: The International Journal of Research into Island Cultures, v6n1: 22-24

Majerle, V (2019) 'Pescatori tradizionali della laguna nord di Venezia e il rapporto con l'ambiente,' (unpublished) Master's degree Thesis in Anthropology, University Ca' Foscari of Venice

Marita, A and Suzuki, W (2019) 'Being affected by sinking deltas: changing landscapes, resilience, and complex adaptive systems in the scientific story of the Anthropocene', Current Anthropology n6o: 286-295 
Ministero delle Infrastrutture e dei Trasporti, Magistrato alle Acque di Venezia, Consorzio Venezia Nuova (2010) 'Venezia: il sistema Mose per la difesa dalle acque alte', Venezia: CVN Report

Moore, J.W (2015) Ecologia-mondo e crisi del capitalismo: la fine della natura a buon mercato, Verona: Ombre Corte Editore

Moore, J.W (2017) 'The Capitalocene, part I: on the nature and origins of our ecological crisis', The Journal of Peasant Studies v44 n3: 594-630

Mondardini Morelli, G (ed) (1990) 'La cultura del mare. Introduzione', La Ricerca Folklorica n21: 5-6

Nash, J (2016) 'Introduction: the space of aquapelago', Shima: Aquapelago Anthology: https://www.shimajournal.org/issues/anthologies/Aquapelago-Anthology-Intro.pdf accessed 18th February 2021

Nio Grandi Navi (2021) Homepage: http://www.nograndinavi.it/ - accessed 18th February 2021

Pineau, C (2020) 'Vino "naturale": ricerca e adattamento nell'epoca dell'Antropocene', in Bonifacio, $\mathrm{V}$ and Vianello, $\mathrm{R}$ (eds) Il ritmo dell'esperienza: dieci casi etnografici per pensare $i$ conflitti ambientali, Padova: Cleup: 285-300

Provincia di Venezia (2015) Piano per la gestione delle risorse alieutiche delle lagune della provincia di Venezia, Venezia: Provincia di Venezia

Rapisarda, C (2019) 'L'acqua alta record a Venezia era imprevedibile, dice il CNR', AGI: https://www.agi.it/cronaca/venezia_acqua_alta-6537068/news/2019-11-13/ - accessed 18th February 2021

Rolston, H (1988) Environmental ethics, Philadelphia: Temple University Press

Scaramelli, C (2019) 'The delta is dead: moral ecologies of infrastructure in Turkey', Cultural Anthropology v34 n3: 388-416

Scott, J.C (1998) Seeing like a state: how certain schemes to improve the human condition have failed, New Haven: Yale University Press

Strang, V (2004) The meaning of water, Oxford-New York: Berg

Tsing, A.L, Matthews, A.S and Bubandt, N (2019) 'Patchy current anthropology: patchy Anthropocene: landscape structure, multispecies history, and the retooling of Anthropology: an introduction to Supplement 2o', Cultural Anthropology v6o Supplement 20: S186-S197

Vallerani, F (2019) 'Fiumi come corridoi di memorie culturali, saperi idraulici e rappresentazioni' Semestrale di Studi e Ricerche di Geografia v31 n1: 105-118

Vianello, R (2017) ‘La laguna di Venezia e il fenomeno delle acque alte: percezioni e conflitti' in Zola, L (ed) Ambientare, Franco Angeli: Torino: 197-219 


\section{Vianello - MOSE machine}

Vianello, R (2018) L'oro nero della laguna di Venezia: la mitilicoltura tra eredità culturali e nuove tradizioni, Roma: Aracne

Vianello, R (2020) 'Mo.S.E. (Modulo Sperimentale Elettromeccanico). Un conflitto tra saperi locali e saperi tecnici nella laguna di Venezia', in Bonifacio, V and Vianello, R (eds) Il ritmo dell'esperienza: dieci casi etnografici per pensare i conflitti ambientali, Padova: Cleup: 129-160 